\section{Exciting and Challenging Times for Chemists and Chemistry}

\author{
by Leiv K. Sydnes
}

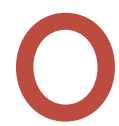

$\mathrm{n}$ a number of occasions since the General Assembly (GA) in August 2003, I have wondered how ideas discussed in Ottawa to promote the chemical sciences and serve our societies can be implemented with maximum effectiveness. I now realize that there is more than one answer to the question because societies are organized very differently around the world and because national and personal priorities vary considerably. Of course, this has consequences for a global organization like ours: IUPAC can mainly be a provider that, to a large extent, has to rely on engaged chemists around the world to reach national stakeholders in a proper and adequate fashion.

In this perspective, opinions expressed during the discussion of my Vice President's Critical Assessment in Ottawa and input received afterwards have been most encouraging: People are willing to serve and become engaged in IUPAC activities. Therefore, I feel that an important task as president will be to act as a facilitator of initiatives and actions aimed at advancing the chemical sciences worldwide and contributing to the application of chemistry in the service of Mankind. As initiatives are required in a number of areas there should be plenty of opportunity for interested chemists to participate in IUPAC activities. I would like to focus on four such areas.

\section{Projects}

For the very existence of the Union, a most important task is to improve our means of generating new, good projects that address scientific issues requiring either international standardization (e.g., nomenclature, terminology, and quantities) or evaluation and critical assessment of quantitative data. In this work, the divisions must play an active role under the leadership of the division committees. This is in line with what a past president of the Analytical Chemistry Division, Folke Ingman, wrote in the last issue of the division's newsletter Teamwork <www.iupac.org/divisions/V/ Teamwork>: "I believe that the division committee must take on the responsibility for producing project ideas and nursing them until a task group has been appointed and a proposal has been put forward."

Ingman's emphasis of the divisions' say in the composition of task groups is important. It is well docu- mented, generally speaking, that the countries with the highest representation in IUPAC governing bodies have by far the most members in the project task groups. As stated by a number of participants at the GA, it is important to correct this imbalance. This is easier said than done, but it is my hope that by improving contacts between the divisions and the chemical communities in the IUPAC member countries-and through the work of the Union Advisory Committee and by meeting with the National Adhering Organizations of member countries-the geographic base of the task groups will broaden considerably. Let us be active in our search for qualified volunteers who are willing to serve IUPAC.

\section{Conferences}

I also would like to see IUPAC become more visible at conferences and utilize them more effectively to make our Union better known in the chemical profession; to disseminate recommendations, technical reports, and reports from task groups; and to develop ideas for new projects. In order to achieve this, IUPAC should, in fact, attach strings to its support of conferences, so that at least one session during a conference is dedicated to discussing the need for standardization or critical assessment of quantitative data, or for exploring if new, exciting scientific topics related to the conference theme and beyond, are about to emerge. If such sessions were organized skilfully by the appropriate division(s) they would gradually prepare younger chemists to develop new materials, devices, and methods for improving sustainable development and quality of life.

\section{Public Appreciation}

In today's media-sensitive societies, the issues of rating, standing, and reputation are important to consider. In doing so we realize that the chemical enterprise suffers from a dubious public image. Chemicals are too often associated with bad things happening to people and the environment, and in recent years, with chemical warfare. Unfortunately, the daily, positive contributions from chemistry and chemical engineering-to society and every one of us-are barely publicized, even though they are instrumental in feeding us, clothing us, housing us, healing us, and even entertaining us.

A number of industrial and chemical organizations have tried-on their own-to alter this perception by presenting a more balanced picture of the benefits and risks of chemicals. Considering the relatively low return from all of these efforts and expenses, it seems reasonable to ask whether some coordination of the activity would be beneficial. Secondly, could IUPAC, an organi- 
zation with a global reputation of providing authoritative and unbiased chemistry information, offer added value and be regarded as more trustworthy in such an effort. In order to try to answer these and a number of related questions, IUPAC has funded a feasibility study entitled "Chemistry's Contributions to Humanity." The task group, chaired by Dr. Edwin D. Przybylowicz, has a wide membership, including several chemists involved in the Committee on Chemistry Education, led by Prof. Peter Atkins. The project description, available at $<$ www.iupac.org/projects/2003/2003-022-1$020 . h t m l>$, reveals the enormity of the task. Any input that will help make the feasibility study more complete will be very much appreciated. Therefore, I urge you to read the project description and supply information to Dr. Przybylowicz, any other member of the task group, or the IUPAC secretariat, in due course.

\section{The Web}

IUPAC is blessed with an outstanding Web site, which we hope will become even better and more valuable. One thing that is missing, however, is a complete set of links to the homepages of all the chemical societies in the IUPAC member countries. Such links-frequently sought by chemists in academia and industry (as well as by representatives at the last GA)-are very useful, but are often hard for individuals to obtain because they may not know the name of an organization in the language of the country it represents. I therefore urge every reader to check <www.iupac.org/links/> to see if the information from his or her country is complete, and if it is incomplete, to encourage the right person(s) in his or her country to furnish the information to IUPAC.

\section{Contact}

As mentioned in the beginning, I regard facilitation to be an important task for the president of the Union. In order to help the chemical community use IUPAC more actively, adequate input is required. Of course a fair amount of information comes through the divisions and active task groups, but I know that IUPAC's officers appreciate constructive comments and ideas from individuals who care to write. Such messages are most welcome, and I therefore challenge you to write to me<leiv.sydnes@kj.uib.no> or to any of the other officers and present what you have in mind during my presidential appointment. I am looking forward to a fruitful relationship for the benefit of IUPAC!

Leiv K. Sydnes <leiv.sydnes@kj.uib.no〉 is the current IUPAC president, a member of the Norwegian Chemical Society, and professor at the University of Bergen.

\section{4-2005 Bureau}

\section{Officers}

Prof. Leiv K. Sydnes, Norway President

Prof. Bryan R. Henry, Canada Vice President

Prof. David StC. Black, Australia Secretary General

Dr. Christoph F. Buxtorf, Switzerland Treasurer

Prof. Pieter S. Steyn, South Africa Past President

\section{Elected Members}

Prof. Chunli Bai, China/Beijing

Prof. S. Chandrasekaran, India

Prof. Robert G. Gilbert, Australia

Prof. Werner Klein, Germany

Dr. Anders Kallner, Sweden

Prof. Nicole J. Moreau, France

Prof. Oleg M. Nefedov, Russia

Dr. Edwin P. Przybylowicz, United States

Dr. Alan Smith, United Kingdom

Prof. Gus Somsen, Netherlands

\section{Division Presidents}

Prof. Ron D. Weir, Canada

Physical and Biophysical Chemistry

Dr. Gerd M. Rosenblatt, United States Inorganic Chemistry

Prof. Minoru Isobe, Japan Organic and Biomolecular Chemistry

Prof. Robert F. T. Stepto, United Kingdom Macromolecular

Prof. H. Kipton J. Powell, New Zealand Analytical Chemistry

Dr. Kenneth D. Racke, United States Chemistry and the Environment

Prof. Paul W. Erhardt, United States Chemistry and Human Health

Dr. Alan D. McNaught, United Kingdom Chemical Nomenclature and Structure Representation

\section{Ex Officio Members}

Prof. Peter W. Atkins, United Kingdom Committee on Chemistry Education

Dr. John M. Malin, United States CHEMRAWN Committee

Dr. David A. Evans, United Kingdom Committee on Chemistry and Industry 